\title{
BOOK REVIEW OF WOLFGANG WEIDLICH'S SOCIODYNAMICS: A SYSTEMATIC APPROACH TO MATHEMATICAL MODELLING IN THE SOCIAL SCIENCES
}

TAYLOR \& FRANCIS, LONDON, 2002, 380 PAGES

REVIEWED BY J. BARKLEY ROSSER JR.

Received 26 January 2005

This volume represents a magnum opus by Wolfgang Weidlich, summarizing his long work in the area of sociodynamics. It lays out the origins and development of his ideas on this topic, presents a variety of applications drawn from his previous work, and offers some new insights and suggestions. For those acquainted with Professor Weidlich's work, it is a satisfying summing-up. For those unacquainted with it, the book provides a good overview and discussion of what is involved in it, both its weaknesses and its strengths. It has a definite predecessor, Weidlich's 1983 book with his frequent coauthor, Günter Haag, Concepts and Models of a Quantitative Sociology, but the book we are discussing here goes well beyond the arguments and models presented in that volume.

The book contains three parts and twelve chapters. The first part, with three chapters, discusses general background issues. The first chapter provides the philosophical and historical origins, particularly from general systems theory and synergetics. Weidlich's long association with the founder of synergetics, Haken [2], is discussed, with synergetics being seen as an extension of general systems theory (both of them were associated with the Institute for Theoretical Physics at the University of Stuttgart for many years). In turn, sociodynamics is seen as an extension of synergetics into the social sciences realm. The second chapter rather briefly discusses some criticisms of quantitative modeling of the sociodynamics sort, including the especially "physicalist" critique, the argument that such models merely transfer physics ideas mindlessly into social sciences. Unfortunately, this chapter does not deal with some of the more substantive criticisms of sociodynamics to be discussed below.

The third chapter presents the standard mathematics of the sociodynamics models of Weidlich. This ultimately involves a particular example deriving a master equation that describes the evolution of probability distributions. Particularly important is the evolution of the mean-value equations that can depict expected outcomes over time. These equations operate in a stochastic framework, which is supposed to represent the actions of the individuals or other lower-level units in the system. Following synergetics, trends in order parameters usually determine the overall outcomes. Also like synergetics, nonlinear interrelationships are assumed that allow for discrete phase transitions, a deep theme of sociodynamics and one of its more appealing aspects. Much of the emphasis is on these 
phase transitions and how different scenarios of trends in order parameters lead to qualitatively different outcomes. The original model of such phase transitions in synergetics was the emergence of coherent fluctuations in a LASER (a word which word Weidlich usefully reminds us that it is actually an acronym).

The second part consists of applications, and its six chapters occupy a full 265 pages of the 380 in the book, the overwhelming majority of its content. The fourth chapter focuses on the migration dynamics between two populations, the fifth on competition between social groups, the sixth on political phase transitions, the seventh on quality competition between high-technology firms, the eighth on fashion demand dynamics, and the ninth on urban evolutionary dynamics.

The three chapters of the third part focus specifically on mathematical issues, with the longer tenth chapter especially on the master equation, and with the shorter eleventh and twelfth on mean value and quasi-mean value dynamics. I will return to talk about some of the second part chapters and then deal with some broader issues.

Chapter 5 focuses on migration between culturally distinct groups and introduces some speculations by Weidlich about Hitler and the relations between Germans and Jews, a matter discussed more later. A first-pass analysis shows three broadly possible outcomes, homogeneous integration of the groups, full segregation of the groups, and a limit cycle outcome of "invasion-evasion-migration." Agglomeration parameter strengths are crucial to which outcome occurs. Then the possibility of chaotic migratory dynamics is investigated. Finally, an empirical analysis drawing on studies of regional migration in Germany is discussed, with evidence of scaling phenomena occurring. This is one of the few places in the book where such empirical work is carried out, with the relative paucity of such being an arguable weakness of the book.

After the fifth one, Chapter 6 on the rise and fall of interacting social groups looks like basically a minor variation, although a large number of variables get talked about. Three scenarios are studied, of cycles, chaos, and "delusive long-term stability." A problem here is that there are so many variables involved that it is hard to pin down what is really crucial and what is not.

The sixth chapter is arguably the most interesting in the book, and contains some of the newest material in terms of Weidlich's own work. Here, he more thoroughly discusses the history of the rise of Hitler in Germany. This becomes the foundation for his model of political phase transitions, with the two different systems being categorized as liberal and totalitarian. The scenario involves initial destabilization of a system, then a period "on the verge" dominated by stochastic fluctuations, interpreted as behavior of key individuals (especially Hitler in the German example), and then the transition. He lays out quite a variety of possible scenarios, including a "balanced opinion" one, and also notes the possibility of "inverse transition," from totalitarianism to liberalism. Although he does not mention it, the transition of the socialist world would seem to fit this, a bit surprising given that Weidlich himself lived for part of his youth in the former East Germany when it was such a state. My biggest frustration with the work in this chapter is that he did not more clearly bring in the economic factors that underlay the move to the critical state, although he did mention it in his verbal discussion. Almost certainly, Hitler would have had no chance of coming to power if there had been no Great Depression. 
In the seventh and eighth chapters, he moves into economics with somewhat similar studies of quality competition between high-tech firms and fashion dynamics. The former is linked to the "Schumpeterian clock" idea. A potential weakness of the sociodynamics approach can be seen here. Something coming from synergetics is the need to distinguish slowly moving order variables and rapidly moving slaved variables. However, sometimes it is not clear that the division is accurately done. Thus, in the quality competition model, supply is made into a slaved variable while changes in demand are an order parameter that drives the system in conjunction with quality variation. Now, it is true that supply can sometimes adjust quickly, but in the short run it is well known that sometimes demand can change almost overnight. In most industries, there are time lags involved in production. When one starts to drag in longer-term production, with capitalstock varying, these lags can become much longer, several years in length. It may well be that over the longer term, the mutual evolution of demand and quality is fundamental, but the supply side seems to be a bit arbitrarily short-shrifted here.

The ninth chapter is another that I especially like, focusing on the regional science problems of urban evolution driven by population pressure. There is a study of both the rural-urban migration dynamic and then of the evolution of internal urban structure and formation. This largely draws on previous work by Weidlich and others, especially Haag, however, it is one of the few places in the book where there is a link with the substantially parallel work carried out by the group around Ilya Prigogine in Brussels (see Allen and Sanglier [1]), which preceded that of the Stuttgart group. However, for both of these groups, there has been an unfortunate problem, that their work has not been recognized by those who have touted the "new economic geography," which largely uses ideas found in this earlier work. Most observers credit Paul Krugman with developing this field, but he and his followers did so without any citation to this clearly relevant earlier work (see Rosser [3]).

There are some difficulties with all this that should be noted. One that has been hinted at is the relative lack of empirical work related to or based on sociodynamics. Of course one cannot expect Professor Weidlich to do everything, and thus he should not be blamed for this. As already noted, the main area where such applications have occurred has been in relation to the migration models, and thus also to some of the regional models as well. The question that arises is to what degree this relative lack of empirical work is related to the nature of sociodynamics models themselves. What occurs to this observer is that in general, it is not very easy to empirically estimate many of the transition probabilities that are crucial to many of the models. In short, there may be a deeper problem here that places limits on the ultimate applicability of the idea.

There is a curious link here with the discussion in Chapter 2 of the potential difficulties of the approach. Weidlich lists as the last of such difficulties the issue of "instrumentalism." By this, he means the possibility that somebody might use sociodynamics to manipulate people in society to achieve certain outcomes. However, most philosophers of science use the term instrumentalism to mean judging theories by how well they forecast reality. If in fact sociodynamics is not very good at making forecasts of real events in real situations, there is certainly little danger that it will be used in the perniciously instrumental manner that concerns Professor Weidlich. 
The other major problem, which is admitted in various places in the book, is the lack of modeling of the behavior of microeconomic agents. Now there are arguments of not doing so, such as that the usual models of individual behavior, especially the rational models of economics, are unrealistic. The new classical school of macroeconomics has created a largely worthless cottage industry out of the idea that one can model a macroeconomy as behaving like a single rational individual. Modern complexity theory, of which sociodynamics can be identified as a part, emphasizes the heterogeneity of agents in the economy and society. This is more realistic. However, many other complexity approaches specifically model these individuals and then allow their interactions to generate the emergent aggregate phenomena. Sociodynamics seems to hark back to older traditions that simply model at the aggregated level directly, leaving at least this observer with a lingering uneasiness.

The specific way that Weidlich argues that individual behavior enters into his models is through the stochastic element. He argues that near critical points, these fluctuations can determine which state a system can end up in, specifically in the case of the political phase-transition model. Thus, Hitler is seen to be a "worst-case accident" (page 150), but I confess to find this to be not entirely satisfying. Weidlich may be right that individuals can only push systems across major transitions when the system has already gotten near a phase-transition boundary, as the Great Depression moved Germany to such a state. But this seems to leave out the possibility that the trends of the order parameters themselves may be altered by changes in individual behavior. In any case, all models have their limits, and Weidlich himself recognizes that sociodynamics only deals with aggregated phenomena rather than individual outcomes.

On the other hand, there is much to praise here. Weidlich was the first to apply the master equation to social science phenomena. Using this, he has been able to model a wide variety of phenomena and to show how well-known outcomes might well arise and transpire in a dynamic context. While analysis of bifurcations and multiple equilibria has become more common in recent years in the social sciences, Weidlich has done an excellent job of focusing on how phase transitions can occur and he has been a genuinely original innovator in this area. He deserves considerable credit for his efforts. This book represents an excellent summary of these efforts.

I wish to add a final point. Given that this book roughly corresponded to Professor Weidlich's retirement from Stuttgart, the book contains more personal observations and references than one usually encounters in a scientific work. However, Professor Weidlich has had an unusually interesting life and an unusually broad intellectual background and perspective. Thus these observations add a degree of interest that is also not usually encountered in such works. It is an admirable work worthy of admiration.

\section{References}

[1] P. M. Allen and M. Sanglier, Urban evolution, self-organization and decision making, Environment \& Planning A 13 (1981), 167-183.

[2] H. Haken, Synergetics-An Introduction. Nonequilibrium Phase Transitions and Self-Organization in Physics, Chemistry and Biology, Springer-Verlag, Berlin, 1977. 
[3] J. B. Rosser Jr., Book review of development, geography, and economic theory by Paul Krugman, J. Econom. Behavior Organization 31 (1996), 450-454.

[4] W. Weidlich and G. Haag, Concepts and Models of a Quantitative Sociology, Springer Series in Synergetics, vol. 14, Springer-Verlag, Berlin, 1983.

J. Barkley Rosser Jr.: Economics Program, College of Business, James Madison University, MSC 0206, Harrisonburg, VA 22807, USA

E-mail address: rosserjb@jmu.edu 


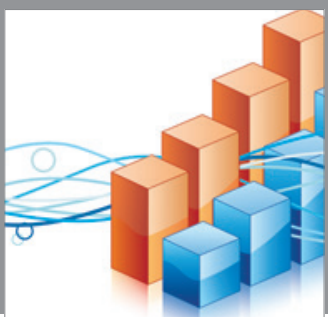

Advances in

Operations Research

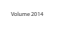

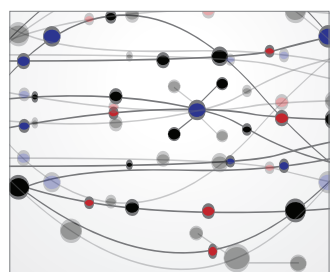

\section{The Scientific} World Journal
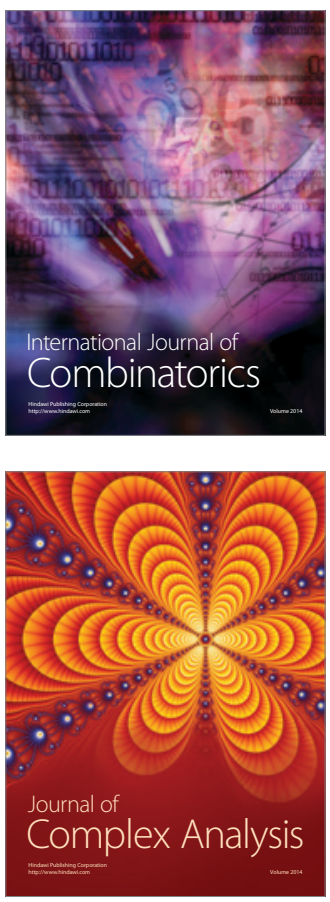

International Journal of

Mathematics and

Mathematical

Sciences
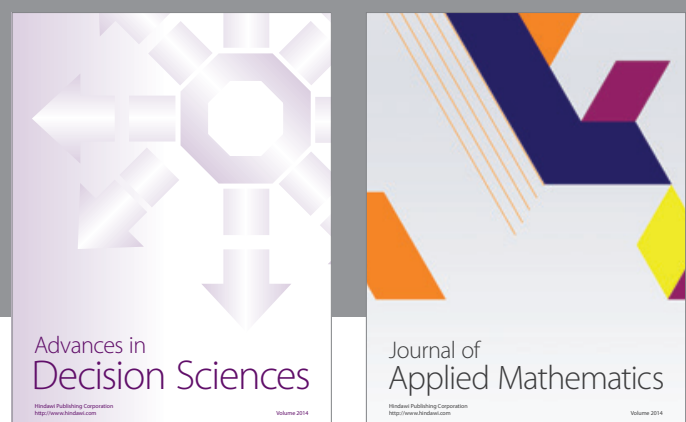

Journal of

Applied Mathematics
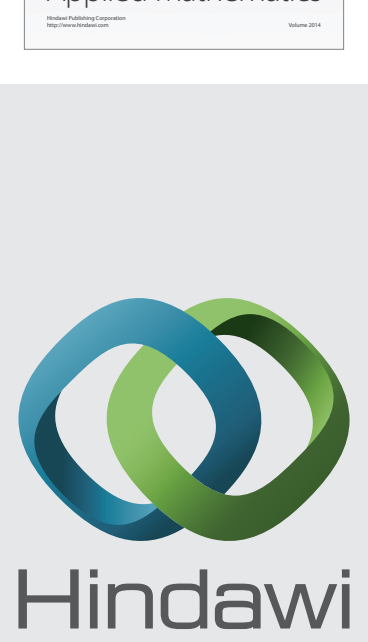

Submit your manuscripts at http://www.hindawi.com
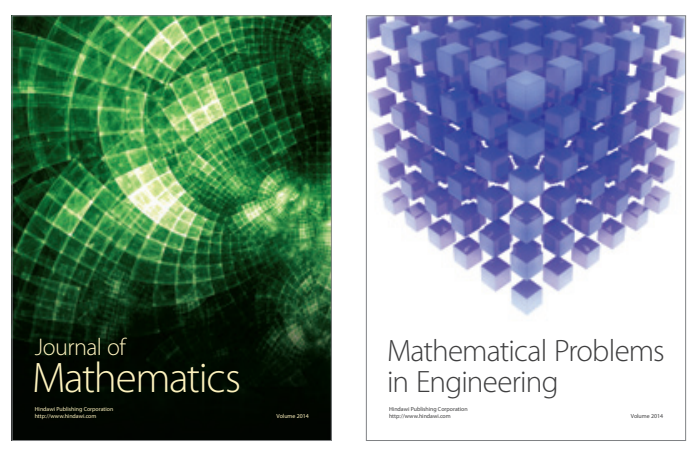

Mathematical Problems in Engineering
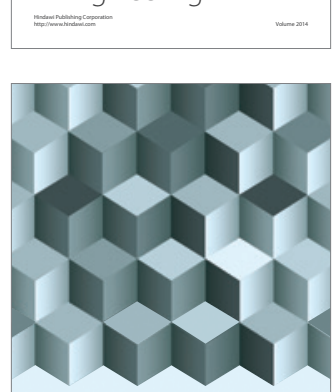

Journal of

Function Spaces
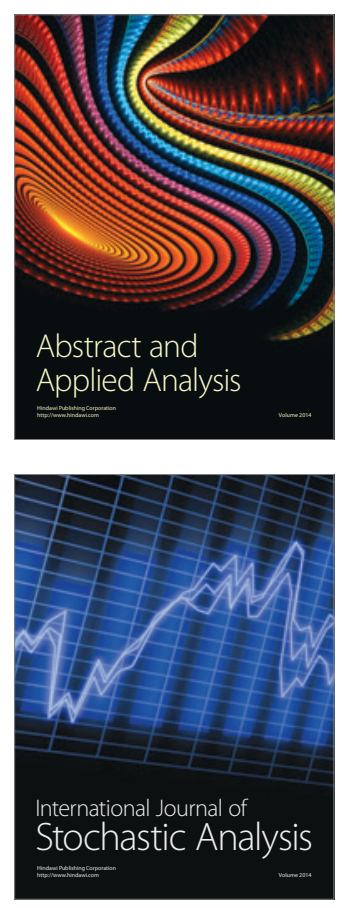

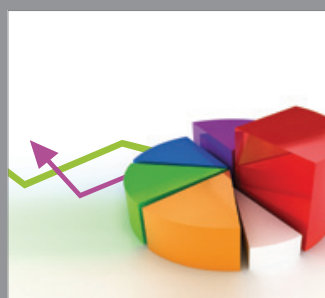

ournal of

Probability and Statistics

Promensencen
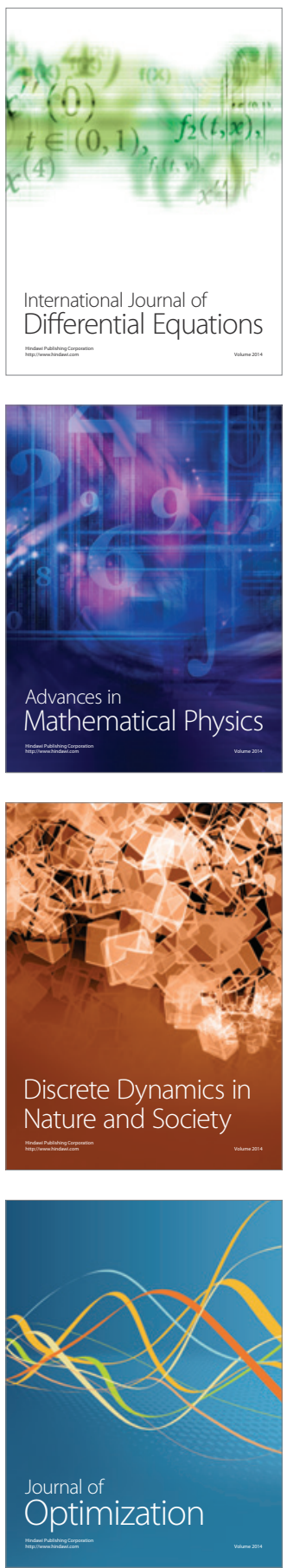